\title{
Clinical and Reproductive Pathological Changes Associated with Brucella melitensis and its Lipopolysaccharides in Female Mice Via Oral Inoculation
}

\author{
${ }^{1,3}$ Faez Firdaus Jesse Abdullah, ${ }^{1,5}$ Lawan Adamu, ${ }^{1}$ Nur Hazirah, \\ ${ }^{1}$ Abdinasir Yusuf Osman, ${ }^{1}$ Rozaihan Mansor, \\ ${ }^{1,3}$ Abdul Wahid Haron, ${ }^{2}$ Mohd Zamri Saad, ${ }^{4}$ Abdul Rahman Omar and ${ }^{1}$ Abdul Aziz Saharee
}

\author{
${ }^{1}$ Department of Veterinary Clinical Studies, \\ ${ }^{2}$ Department of Veterinary Pathology and Microbiology, \\ Faculty of Veterinary Medicine, Universiti Putra Malaysia, 43400 UPM Serdang, Selangor, Malaysia \\ ${ }^{3}$ Research Centre for Ruminant Disease, \\ Faculty of Veterinary Medicine, Universiti Putra Malaysia, 43400 Serdang, Selangor, Malaysia \\ ${ }^{4}$ Institute of Bioscience, Universiti Putra Malaysia, Serdang, Selangor, Malaysia \\ ${ }^{5}$ Department of Veterinary Medicine, \\ Faculty of Veterinary Medicine, University of Maiduguri, PMB1069, Borno State, Nigeria
}

Received 2013-06-19, Revised 2013-07-20; Accepted 2013-07-24

\begin{abstract}
Brucella melitensis (B. melitensis) are Gram-negative, aerobic, facultative intracellular bacteria that cause brucellosis that usually leads to abortion in sheep and goats. Three groups of equal number of 24 healthy female mice were used as animal models. They were orally inoculated with $0.4 \mathrm{~mL}$ of phosphate Buffered Saline (PBSControl group), $0.4 \mathrm{~mL}$ of $10^{9} \mathrm{cfu}$ of $B$. melitensis and $0.4 \mathrm{~mL}$ of Lipopolysaccharides (LPS) extracted from $10^{9} \mathrm{cfu}$ of $B$. melitensis (both as treatment groups). Clinical signs exhibited by the mice were observed for 10 days, after which the survived mice were euthanized by cervical dislocation. Following that, post mortem was conducted and histopathological study of the reproductive organs was carried out. B. melitensis group showed mild clinical signs compared to LPS group which showed normal behaviours except for mild ruffled fur, 14 and $34 \mathrm{~h}$ post-inoculation, respectively. The control group (PBS) showed normal behaviours. Histopathology results revealed that both $B$. melitensis and LPS groups showed mild to moderate infiltration of inflammatory cells in the reproductive organs, along with normal to mild findings of necrosis. Mild to moderate haemorrhage were found in the mice of $B$. melitensis group, while LPS group showed normal to mild haemorrhage and moderate to severe congestion of the ovary. The study proved that mice infected orally with $B$. melitensis developed mild clinical signs whereas mice orally inoculated by its LPS showed normal behavior except for the mild ruffled fur. Moreover, both groups of mice inoculated with $B$. melitensis immunogens developed pathological changes in the reproductive organs. The LPS of $B$. melitensis could be a potential candidate for the development of vaccines.
\end{abstract}

Keywords: B. Melitensis, Lipopolysaccharides, Female Mice, Histopathology, Reproductive Organs

\section{INTRODUCTION}

Brucellosis is one of the most important infectious diseases caused by Brucella sp. that affects humans as well as domestic and wild animals, with reproductive disorders as the main problem in domestic animals (Megid et al., 2010; Silva et al., 2011). The validly published species of Brucella are B. melitensis, B.

Corresponding Author: Faez Firdaus Jesse Abdullah, Department of Veterinary Clinical Studies, Faculty of Veterinary Medicine, University Putra Malaysia, 43400 UPM Serdang, Selangor, Malaysia Tel: +60389463924 
abortus, B. suis, B. ovis, B. canis and B. neotome (Lopes et al., 2010); with Brucella melitensis and Brucella ovis as the main causes of brucellosis in sheep and goats (Megid et al., 2010). Brucella melitensis are Gram-negative, aerobic, partially acid fast and facultative intracellular coccobacilli or short rods bacteria that cause brucellosis in sheep and goats and also the most common species that infect humans (Yohannes et al., 2013). Brucellosis infection in goats and sheep causes abortion, stillbirths, the birth of weak offsprings and infertility of the females while the males usually develop orchitis, epididymitis, seminal vesiculitis and also infertility (Megid et al., 2010). At herd level, there will be a general decrease in herd fertility, an increase in lamb or kid mortality with a low weaning percentage, a decrease on milk production and an increased culling of males due to chronic lesion on reproductive organs (Megid et al., 2010).

B. melitensis infection in sheep and goats occurs mainly through the mucous membrane of nasopharynx, apart from vertical transmission from the dam to the offsprings through "in uterus" or via the ingestion of colostrums or milk. The pathogens are then shed to the environment in large numbers through the placenta, vaginal fluids and milk (Megid et al., 2010). This facultative intracellular bacterium is able to invade into and survive within macrophages and non-professional phagocytes which results in its ability to cause chronic infection in the host (Paixao et al., 2009; Sa et al., 2012). Brucella does not evade phagocytosis by macrophages or neutrophils but inhibits the degranulation of both primary and secondary neutrophil granules and the myeloperoxidase-hydrogen peroxide-halide system.

As in other Gram-negative bacteria, the Lipopolysaccharide (LPS) in brucellae is one of the most biologically active and an important component of the outer membrane (Seyed et al., 2011) and it is the major virulence factor of Brucella (Carlos et al., 2011). B. melitensis may occur as either smooth or rough variants depending on the expression of O-Polysaccharides (OPS) as a component of the bacterial outer membrane LPS (Martin-Martin et al., 2011; Akhtar et al., 2012). The smooth LPS (S-LPS) are composed of three domains: the lipid $A$, the core oligosaccharide and the immunodominant portion of the molecule-the $\mathrm{O}$ side chain, also called the $O$ antigen (Seyed et al., 2011). Apart from the ability to avoid the killing mechanism within macrophages, the low biological activity induced by Brucella S-LPS might be one of the factors contributing to the survival of these pathogens in phagocytic cells (Lopes et al., 2010; Akhtar et al., 2012).

Previously, Abdullah et al. (2013) has conducted a similar study in male mice intraperitoneally inoculated with Brucella and its LPS and it has shown significant changes in male reproductive organs. However, information on clinical response and reproductive pathology in female mice orally inoculated with Brucella and its LPS is scarce. Therefore, this study aims to investigate on the clinical and cellular changes in reproductive organ of female mice following oral inoculation with wild type $B$. melitensis and its LPS

\section{MATERIALS AND METHODS}

\subsection{Brucella Melitensis Culture}

The Brucella melitensis used in this study were obtained from stock culture from a previous outbreak of brucellosis in Malaysia was. The bacteria was then recultured on Brucella Agar which contains growth supplements; namely biotin, thiamin and nicotinamide. The optimum growth temperature is $36-38^{\circ} \mathrm{C}$ whereby the colonies can be visible after 2-4 days of incubation.

\subsection{Preparation of $10^{9} \mathrm{Cfu}$ of Brucella Melitensis}

Preparation of $10^{9}$ cfu of $B$. melitensis was done by adding distilled water onto pure cultures of $B$. melitensis before the bacteria was transferred into sterile test tubes. These sterile test tubes were then compared with Mac Farland standard to determine the $10^{9} \mathrm{cfu}$ of $B$. melitensis.

\subsection{LPS Extraction from $10^{9}$ of Colony of Brucella Melitensis}

The Lipopolysaccharides (LPS) of B. melitensis was extracted using Intron Biotechnology ${ }^{\circledR}$ LPS extraction kit. In this study, $10^{9} \mathrm{cfu}$ of $B$. melitensis was prepared for LPS extraction. The bacteria were firstly harvested by centrifugation in room temperature at $13,000 \mathrm{rpm}$ for 30 sec. Then, $1 \mathrm{~mL}$ of lysis buffer was added and vigorously vortexed. $200 \mu \mathrm{L}$ of choloform was later added and vigorously vortexed for 10-20 sec before it was incubated for $5 \mathrm{~min}$ in room temperature. Following that, it was centrifuged at $13,000 \mathrm{rpm}$ for $10 \mathrm{~min}$ at $4{ }^{\circ} \mathrm{C}$, whereby $400 \mu \mathrm{L}$ of the supernatant was transferred into a new $1.5 \mathrm{~mL}$ tube. Next, $800 \mu \mathrm{L}$ of purification buffer was added and mixed well with the transferred supernatant after which it was incubated at $-20^{\circ} \mathrm{C}$ for $10 \mathrm{~min}$. It was then centrifuged again at $13,000 \mathrm{rpm}$ 
for $15 \mathrm{~min}$ at $4^{\circ} \mathrm{C}$. The LPS pellet was obtained after the excess supernatant was discarded before the LPS pellet was washed with $1 \mathrm{ml}$ of $70 \%$ ethanol, which was then dried completely. Finally, $70 \mu \mathrm{L}$ of $10 \mathrm{mM}$ Tris-HCl buffer of $\mathrm{pH} 8.0$ was added to the LPS pellet whereby it was dissolved by 2 min of boiling.

\subsection{Experimental Design}

A total of 24 healthy female mice of ICR were used in this study. These mice were divided into 3 equal groups consisting of 8 mice per group. Mice in group 1 were orally inoculated with $0.4 \mathrm{~mL}$ of Phosphate Buffer Saline (PBS) of pH 7; while mice in group 2 were orally inoculated with $0.4 \mathrm{~mL}$ of $10^{9} \mathrm{cfu}$ of $B$. melitensis and mice in group 3 were similarly inoculated with $0.4 \mathrm{ml}$ of LPS of $10^{9} \mathrm{cfu}$ of $B$. melitensis (Picture 1). All of these groups were then observed for 10 days for clinical signs such as ruffled fur, movements, closed eyes and ocular discharge and responsiveness. After the 10 days of observation, survived mice were euthanized by cervical dislocation and reproductive organs; namely ovary, oviduct, uterine body, vagina and vulva; were harvested for histopathological study.

\subsection{Clinical Signs Scoring}

Clinical signs of the three groups observed in this study were scored 0 to 3 based on the presence of ruffled fur, changes in movements, eye closure and presence of ocular discharge, as well as the mice's responsiveness towards stimuli. The score of 0 represents no abnormality, score of 1 represents mild clinical signs, while score 2 and 3 represent moderate and severe clinical signs, respectively.

\subsection{Pathological Lesion Scoring}

Pathological cellular changes were scored following the evaluation of two slides for each organ per mouse. The reproductive organs evaluated were ovary, oviduct, uterine body, vagina and vulva. These organs were examined under $\times 40$ to $\times 400$ magnifications. Histopathological lesions were scored 0 to 3 , whereby 0 $=$ normal, $1=$ mild (lesions involving less than $1 / 3$ of the field), $2=$ moderate (lesions involving $1 / 3$ to $2 / 3$ of the field) and $3=$ severe (lesions involving more than $2 / 3$ of the field).

\subsection{Statistical Analysis}

All the data's were analyzed using Anova, Kruskal Wallis Test and Mann-Whitney U test. The analysis was done using JMP® 9. NC: SAS Institute Inc. software Version. The data were considered significant at $\mathrm{p}<0.05$.

\section{RESULTS}

\subsection{Clinical Signs}

Mice orally inoculated with Brucella melitensis showed mild clinical signs compared to that of control and LPS group, except for mild ruffled fur of mice in LPS group. The onset of clinical signs in group 2 (Brucella) starts at $14 \mathrm{~h}$ of post-inoculation and they presented mild ruffled fur, movements and responsiveness. However, the onset of mild closure of the eyes of the mice in group 2 (Brucella) starts at $18 \mathrm{~h}$ of post-inoculation and the mice in group 3 (LPS) showed no abnormal clinical signs. Mice in group 3 (LPS) only showed mild ruffled fur at $34 \mathrm{~h}$ of postinoculation. All the treatment groups of mice do not manifest severe clinical signs and survived until the end of the study and they were humanely euthanized. The mean scores of observed clinical signs in the mice are presented in Table 1.

Statistical analysis of the clinical signs scoring revealed significant differences $(p<0.05)$ between each group for the parameters (movements, eyes and responsiveness) that are presented in Table 2 . These clinical signs were further analyzed and showed significant differences between group 1 (Control) and group 2 (Brucella) and between group 2 (Brucella) and group 3 (LPS) for changes in movements (Table 3 ).

\subsection{Histopathological Lesion}

Statistical analysis of the histopathological lesions showed significant differences $(p<0.05)$ between groups (Table 4). Further test revealed that there were significant differences between group 1 (Control) and group 2 (Brucella) and also between group 1 (Control) and group 3 (LPS). Meanwhile, significant differences $(\mathrm{p}<0.05)$ for the presence of inflammatory cells were only found between Brucella group and LPS group (Table 5).

Mild to moderate infiltration of inflammatory cells were observed in all the reproductive organs of the Brucella and LPS group. The reproductive organs of Brucella group were found to have mild to moderate haemorrhagic lesions, while mice in LPS group had normal to mild congestion or haemorrhage of the organs except for ovary in which moderate to severe congestions were found. Figure 1 and 2 represent the microscopic lesions of the reproductive organs. 
Table 1. Mean score of clinical signs observed in mice throughout 10 days post-inoculation with immunogens

\begin{tabular}{llll}
\hline Clinical signs & Group 1 (PBS) & Group 2 (Brucella) & Group 3 (LPS) \\
\hline Ruffled fur & $0.00 \pm 0.00$ & $0.26 \pm 0.01$ & $0.28 \pm 0.01$ \\
Movements & $0.00 \pm 0.00$ & $0.23 \pm 0.01$ & $0.00 \pm 0.00$ \\
Closed eyes and ocular discharge & $0.00 \pm 0.00$ & $0.02 \pm 0.01$ & $0.00 \pm 0.00$ \\
Responsiveness & $0.00 \pm 0.00$ & $0.22 \pm 0.01$ & $0.00 \pm 0.00$ \\
\hline
\end{tabular}

Clinical signs scoring: 0 = Normal; 1 = Mild; 2 = Moderate; 3 = Severe

Table 2. Kruskal Wallis Test result on comparison of clinical signs scoring between each group

\begin{tabular}{lllll}
\hline Parameters & Fur & Movements & Eyes & Responses \\
\hline Chi-square & 3.74 & 9.12 & 6.54 & 6.54 \\
Df & 2.00 & 2.00 & 2.00 & 2.00 \\
P-value & 0.15 & 0.01 & 0.04 & 0.04 \\
\hline
\end{tabular}

Test statistics ${ }^{\mathrm{a}, \mathrm{b}}: \mathrm{a}=$ Kruskal Wallis test; $\mathrm{b}=$ grouping variables: group; $\mathrm{df}=$ degree of freedom Significant parameters with value $\mathrm{p}<0.05$ were further analyzed by Mann-Whitney U test

Table 3. Mann-Whitney U Test result on comparison of clinical signs scoring

\begin{tabular}{llll}
\hline Group & Movements $^{1}$ & Closed eyes and ocular discharge $^{2}$ & Responsiveness $^{3}$ \\
\hline PBS & $10.50^{\mathrm{a}}$ & $11.00^{\mathrm{a}}$ & $11.00^{\mathrm{a}}$ \\
Brucella & $16.50^{\mathrm{b}}$ & $15.50^{\mathrm{a}}$ & $15.50^{\mathrm{a}}$ \\
LPS & $10.50^{\mathrm{a}, \mathrm{b}, \mathrm{c}}$ & $11.00^{\mathrm{a}}$ & $11.00^{\mathrm{a}}$ \\
\hline
\end{tabular}

a.b, c; mean ranks in the same column differ at $\mathrm{p}<0.05 ; 1 \mathrm{p}<0.01,2 \mathrm{p}<0.04$ and $3 \mathrm{p}<0.04$ with significant value of $\mathrm{p}<0.05$ (from Kruskal Wallis Test)

Table 4. Kruskal Wallis Test result on comparison of histopathological lesions scoring between each group

\begin{tabular}{llcc}
\hline Parameters & Inflammatory cells & Degenerations/necrosis & Congestion/haemorrhage \\
\hline Chi-square & 84.53 & 22.39 & 44.68 \\
df & 2.00 & 2.00 & 2.00 \\
p-value & 0.00 & 0.00 & 0.00
\end{tabular}

Test statistics $^{\mathrm{a}, \mathrm{b}}: \mathrm{a}=$ Kruskal Wallis test; $\mathrm{b}=$ grouping variables: group; $\mathrm{df}=$ degree of freedom Significant parameters with value $\mathrm{p}<0.05$ were further analyzed by Mann-Whitney $U$ test

Table 5. Mann-Whitney U Test on comparison of histopathological lesion scoring

\begin{tabular}{llll}
\hline Group & Inflammatory cells $^{1}$ & Degeneration/Necrosis $^{2}$ & Congestion/Haemorrhage $^{3}$ \\
\hline PBS & $23.50^{\mathrm{a}}$ & $44.00^{\mathrm{a}}$ & $33.50^{\mathrm{a}}$ \\
Brucella & $90.12^{\mathrm{b}}$ & $70.25^{\mathrm{b}}$ & $73.40^{\mathrm{b}}$ \\
LPS & $67.88^{\mathrm{bc}}$ & $67.25^{\mathrm{b}}$ & $74.60^{\mathrm{b}}$ \\
\hline
\end{tabular}

$\overline{a . b, c}$ mean ranks in the same column differ at $\mathrm{p}<0.05 ; 1,2,3 \mathrm{p}<0.000$ with significant value of $\mathrm{p}<0.05$ (from Kruskal Wallis test)

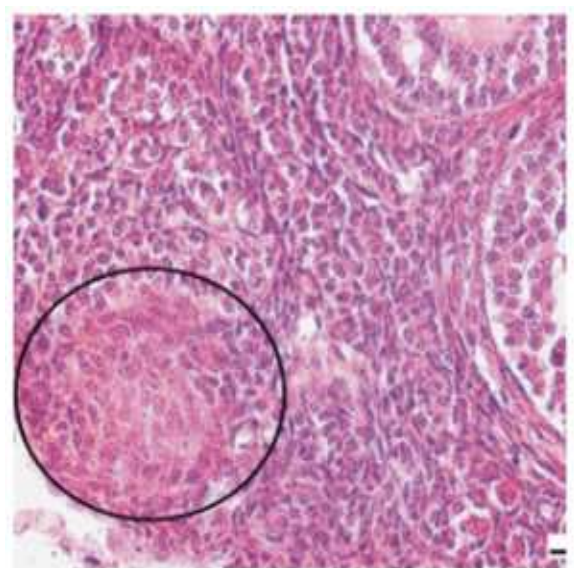

(A)

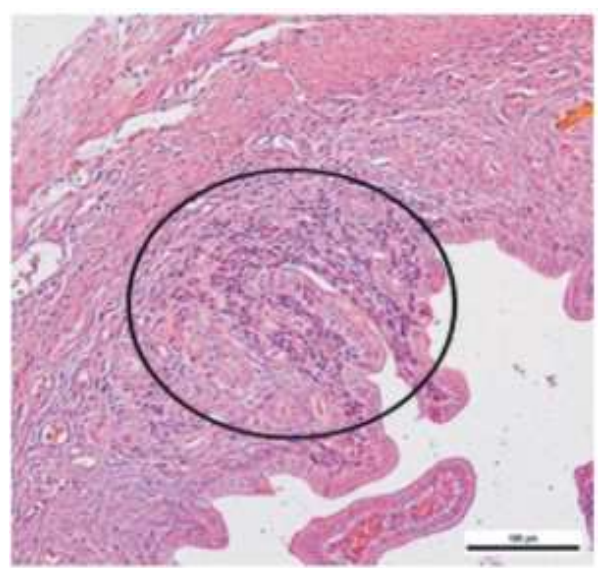

(B) 
Faez Firdaus Jesse Abdullah et al. / American Journal of Animal and Veterinary Sciences 8 (3): 104-111, 2013

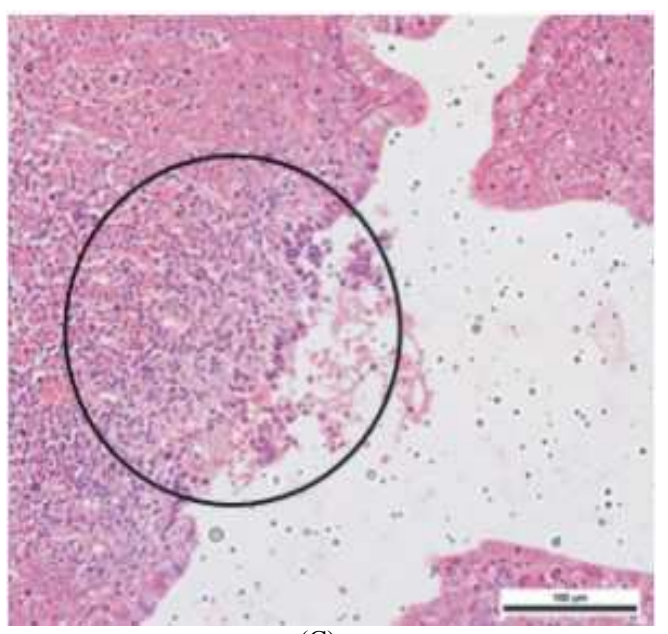

(C)

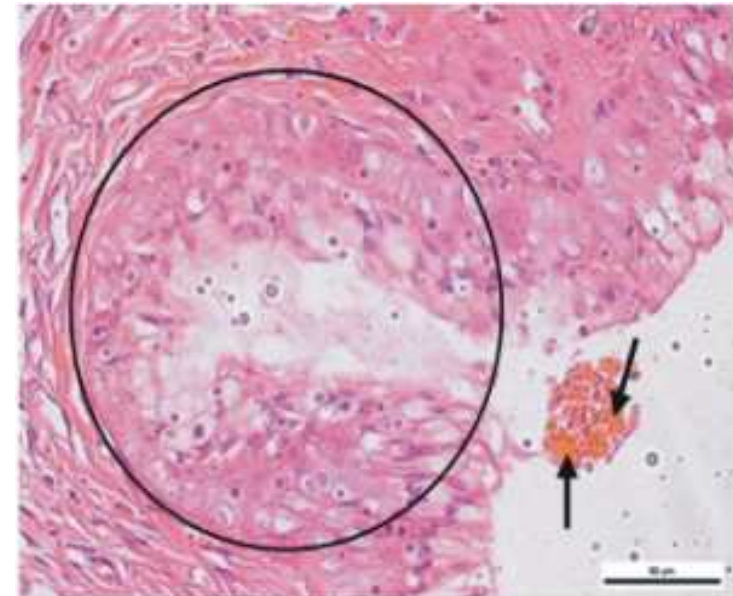

(D)

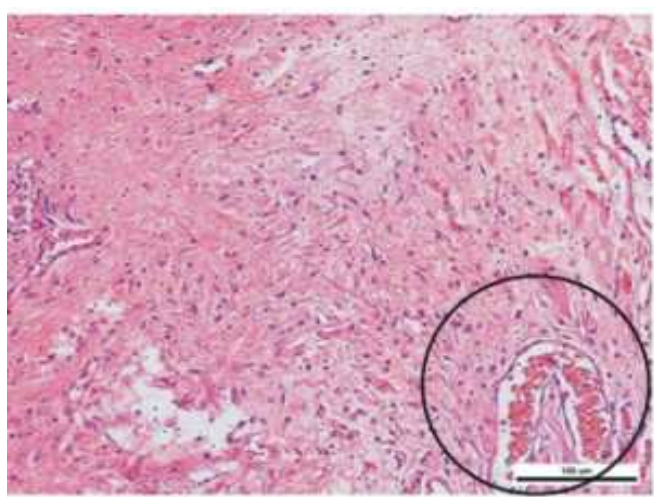

(E)

Fig. 1. Histopathological lesions in reproductive organs of mice in group 2 (Brucella) (A) Necrosis of the lutein cells of ovary; (B) Moderate infiltration of inflammatory cells in the epithelial and submucosal layer of oviduct; (C) Severe infiltration of inflammatory cells and necrosis of the endometrium, (D) Necrosis (circle) and haemorrhage (arrow) of the stratified squamous epithelium; (E) Congested blood vessel of vulva

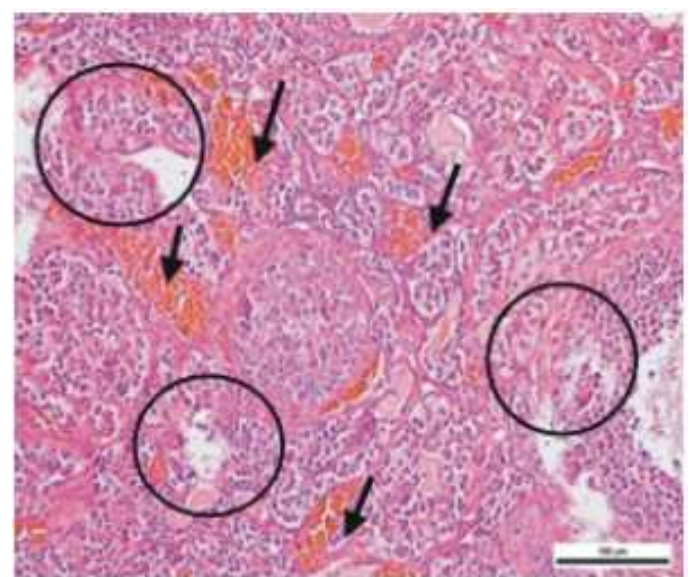

(A)

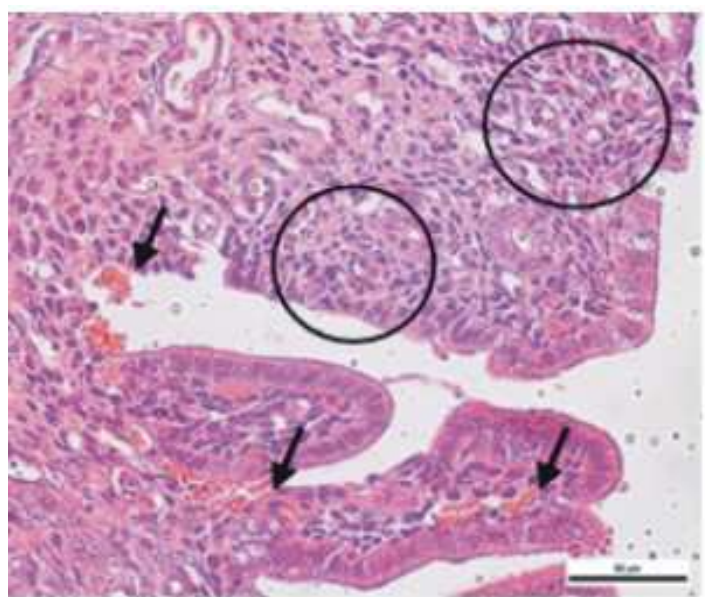

(B) 


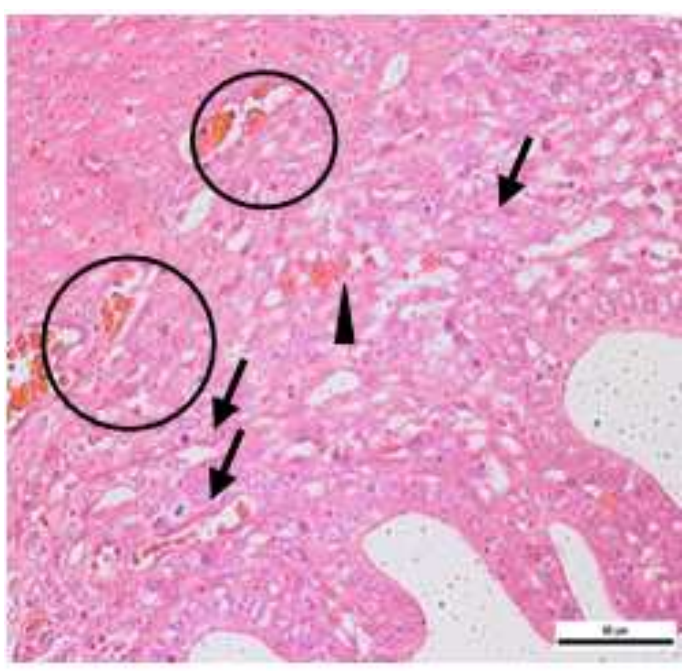

(C)

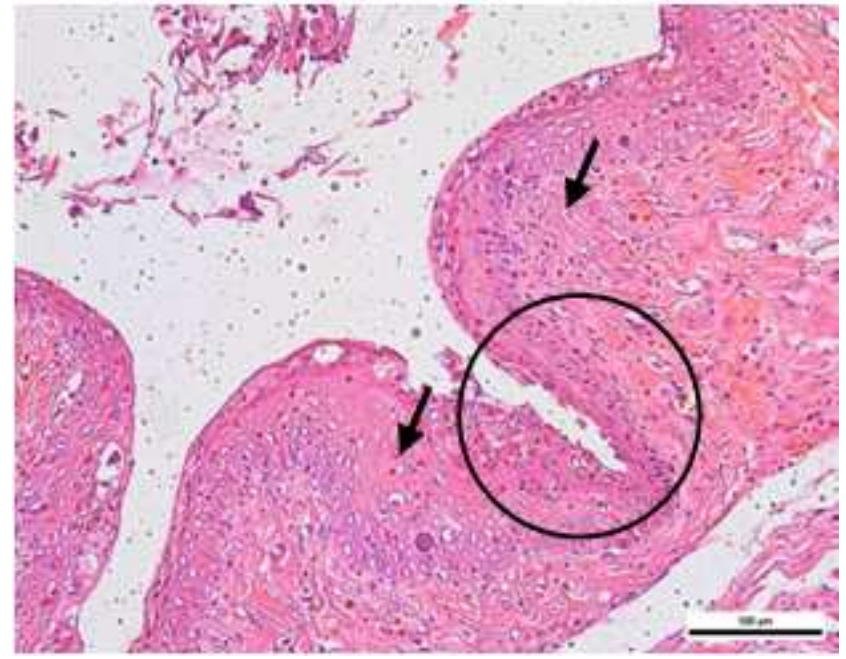

(D)

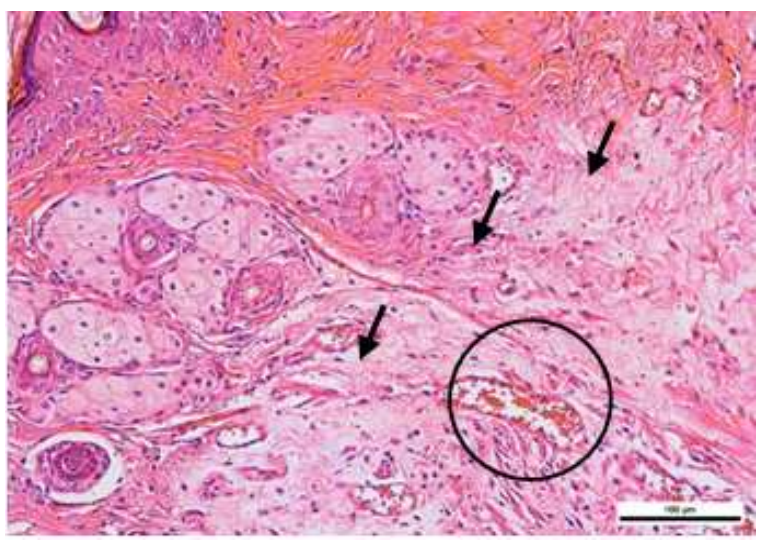

(E)

Fig. 2. Histopathological lesions in reproductive organs of mice in group 3 (LPS) (A) Congested blood vessels (arrow) and necrosis (circle) of the lutein cells in the ovary; (B) Haemorrhage (arrow) and necrosis (circle) of the epithelial layer of the oviduct; (C) Congested blood vessels (circle), haemorrhage (arrowhead) and infiltration of inflammatory cells (arrow) in the endometrium; (D) Mild necrosis (circle) of the stratified squamous epithelium and mild infiltration of inflammatory cells (arrow); (E) Congested blood vessels (circle) and infiltration of inflammatory cells of vulva (arrow)

\section{DISCUSSION}

In this present study, the clinical responses in female mice orally inoculated with wild type Brucella melitensis and its LPS were observed and compared. This study revealed that mice in group 2 which were orally inoculated with $B$. melitensis showed mild clinical signs compared to mice that were inoculated with the bacterial LPS, which only showed mild ruffled fur. In the present study, the mice manifested milder clinical signs compared to a similar study done by Abdullah et al. (2013), who reported manifestation of severe clinical signs in male mice intraperitoneally inoculated with $B$. melitensis, while male mice in LPS group manifested normal to mild clinical signs. Furthermore, a study conducted by Islam et al. (2009) reported that rat intraperitoneally inoculated with $B$. abortus became lethargic, anorexic and febrile within 24 hours. It was also reported that mice intraperitoneally inoculated with $5 \times 10^{8}$ cfu of $B$. melitensis showed extreme shivering, erection of hair coat, anorexia and dullness (Takele et al., 2009).

This study also showed the onset of clinical signs that starts at $14 \mathrm{~h}$ post-inoculation for mice in Brucella group, while mice in LPS group showed mild ruffled fur at $34 \mathrm{~h}$ 
post-inoculation. The onset of clinical signs observed in this study was longer compared to intraperitoneal inoculation of Brucella immunogens (Abdullah et al., 2013). These findings could be explained by a study conducted by Grillo et al. (2012) that stated that only low proportion of bacteria ( 1 to $2 \%$ ) will translocate through the gut cells as the digestive tract holds many defenses towards colonization and multiplication of pathogenic microorganisms (Paixao et al., 2009).

Apart from that, the current study was also conducted to compare the cellular changes in the female reproductive organs of mice inoculated orally with wild type $B$. melitensis and its LPS. This study revealed mild to moderate infiltration of inflammatory cells in all of the female reproductive organs; namely ovary, oviduct, uterine body, vagina and vulva, for both Brucella and LPS group, along with normal to mild findings of degeneration or necrosis in those organs. Congestion or haemorrhage lesions were found to be mild to moderate in all of the reproductive organs of mice in Brucella group, while mice in LPS group has normal to mild congestion or haemorrhage of those organs, except for ovary which showed moderate to severe congestion. These findings proved that oral inoculation of 0.4 $\mathrm{ml} \times 10^{9}$ of Brucella immunogens were able to produce cellular changes in the female reproductive organs, as supported by the study of Grillo et al. (2012) who stated that achievement of infection through oral inoculation needed very large numbers of Brucella $\left(\geq 10^{10}\right.$ cfu/mouse) at about 0.1 to $0.25 \mathrm{~mL}$ per mouse.

Another study conducted by Islam et al. (2009) stated that the histopathological lesions in the uteri of infected pregnant rats were characterized by thickened muscular wall with moderate to diffuse infiltration of inflammatory cells such as lymphocytes, neutrophils, monocytes and macrophages. It was also reported that BALB/c pregnant female mice infected with $10^{6} \mathrm{cfu}$ of B. abortus virulent strain 2308 developed a moderate multifocal necrotic placentitis associated with severe neutrophilic infiltrate and intralesional bacteria in trophoblastic cells (Silva et al., 2011).

The present study has revealed that mice orally inoculated with LPS only showed mild ruffled fur with the average of normal to mild histopathological lesions in the reproductive organs. This is consistent with the statement that the O-polysaccharide of S-LPS from B. abortus is less potent compared to S-LPS from Escherichia coli and thus considered as less likely to induce endotoxic shock in humans (Akhtar et al., 2012).

\section{CONCLUSION}

In conclusion, this study has proved that mice infected orally with $B$. melitensis developed mild clinical signs whereas mice orally inoculated by its LPS showed normal behavior except for the mild ruffled fur. Moreover, both groups of mice inoculated with $B$. melitensis immunogens developed pathological changes in the reproductive organs. Lastly, the LPS of $B$. melitensis could be a potential candidate for the development of vaccines.

\section{ACKNOWLEDGEMENT}

We thank the staff of the Department of Veterinary Clinical Studies, Universiti Putra Malaysia and Research Centre for Ruminant Disease, in particular Yap Keng Chee, Mohd Jefri Norsidin and Mohd Fahmi Mashuri for their assistance. The project was funded by Ministry of Higher Education Malaysia.

\section{REFERENCES}

Abdullah, J.F.F.B., A.A. Saharee, A.R. Omar, J. Sabri and A.W. Haron et al., 2013. Clinico-pathological changes associated with brucella melitensis infection and its bacterial Lipopolysaccharides (LPS) in male mice. Int. J. Anim. Vet. Adv., 1: 1-6.

Akhtar, R., Y.O. He, C.B. Larson, Z.I. Chaudhary and A. Mansur-ud-Din, 2012. Differential stimulatory activities of smooth and rough Brucella abortus lipopolysaccharide in murine macrophages. Pak. Vet. J., 32: 339-344.

Carlos, A.R., C.L., Galindo H.R. and L.G. Adams, 2011. Transcriptional profile of the intracellular pathogen Brucella melitensis following HeLa cells infection. Microb. Pathogen., 51: 338-344. DOI: 10.1016/j.micpath.2011.07.006, PMID: 21798337

Grillo, M.J., J.M. Blasco, J.P. Gorvel, I. Moriyon and E. Moreno, 2012. What have we learned from brucellosis in the mouse model? Vet. Res., 43: 29-29. DOI: 10.1186/1297-9716-43-29, PMID: 22500859

Islam, M.A., M.M. Khatun, B.K. Baek and I. Lee, 2009. Effects of Brucella abortus biotype 1 infection on the reproductive performance of sprague-dawley rats. Pak. J. Biol. Sci., 12: 353-359. PMID: 19579969

Lopes, L.B., R. Nicolino and J.P.A. Haddad, 2010. Brucellosis-risk factors and prevalence: A review. Open Vet. Sci. J., 4: 72-84. 
Martin-Martin, A.I., P. Sancho, C. Tejedor, L. Fernandez-Lago and N. Vizcaino, 2011. Differences in the outer membrane-related properties of the six classical Brucella species. Vet. J., 189: 103-105. DOI: 10.1016/j.tvj1.2010.05.021, PMID: 20576453

Megid, J., L.A. Mathias and C.A. Robles, 2010. Clinical manifestations of brucellosis in domestic animals and humans. Open Vet. Sci. J., 4: 119-126.

Paixao, T.A., C.M. Roux, A.B. Den Hartigh, S. Sankaran-Walters and S. Dandekar et al., 2009. Establishment of systemic Brucella melitensis infection through the digestive tract requires urease, the type IV secretion system and lipopolysaccharide $\mathrm{O}$ antigen. Infect. Immun., 77: 4197-4208. DOI: 10.1128/IAI.00417-09, PMID: 19651862

Sa, J.C., T.M. Silva, E.A. Costa, A.P. Silva and R.M. Tsolis et al., 2012. The virB-encoded type IV secretion system is critical for establishment of infection and persistence of Brucella ovis infection in mice. Vet. Microbiol., 159: 130-140. PMID: 22483850
Seyed, D.S., R.A. Mohammad, K. Sahar, S.S. Mehdi and M. Arfa, 2011. Biological and immunological characteristics of brucella abortus S99 major outer membrane proteins. Jundishapur J. Microbiol., 4: 29-36.

Silva, T.M.A., E.A. Costa, T.A. Paixao, R.M. Tsolis and R.L. Santos, 2011. Laboratory animal models for brucellosis research. J. Biomed. Biotechnol., 2011: 1-9. DOI: $10.1155 / 2011 / 518323$

Takele, B.Y., S.K. Bejo, A.R. Bahaman and A.R. Omar, 2009. Comparison of PCR assay with serum and whole blood samples of experimental trials for detection and differentiation of Brucella melitensis. J. Anim. Vet. Adv., 8: 1637-1640.

Yohannes, M., H. Degefu, T. Tolosa, K. Belihu and R.R. Cutler et al., 2013. Brucellosis in Ethiopia. Afr. J. Microbiol. Res., 7: 1150-1157. DOI: 10.5897/AJMR12.738 